\title{
Dynamics of large ciliate protozoa in the rumen of cattle fed on diets of freshly cut grass
}

\author{
BY R. A. LENG \\ Department of Biochemistry, Microbiology and Nutrition, Faculty of Rural Science, \\ University of New England, Armidale, NSW 2351, Australia \\ AND D. DELLOW AND G. WAGHORN \\ DSIR, Private Bag, Palmerston North, New Zealand
}

(Received 7 April 1986 - Accepted 21 April 1986)

\begin{abstract}
1. The dynamics of large ciliate (holotrich) protozoa (Isotricha and Dasytricha spp.) in the rumen of cattle given cut, fresh ryegrass (Lolium multiflorium Lam) were studied by means of a single intrarumen injection of ${ }^{14} \mathrm{C}$-labelled protozoa prepared in vitro by adding $\left[\mathrm{Me}^{14} \mathrm{C}\right]$ choline to rumen fluid containing protozoa and incubating at $39^{\circ}$ for $2 \mathrm{~h}$.

2. An indication of the lysis rate of protozoa in the rumen was obtained from the radioactivity apparently lost through the methane pool.

3. The turnover time of the holotrich protozoa indicates that these protozoa were extensively retained in the rumen and that only a small proportion of those produced in the rumen flowed out in the digesta. This was supported by the estimation of the rate of lysis which was approximately $85 \%$ of the turnover rate in the rumen.

4. The apparent production rate of the larger protozoa indicates that they contribute only about $9 \%$ of the predicted net microbial protein synthesis in the rumen.
\end{abstract}

Protozoa are nearly always present in the rumen, their population densities varying with diet and frequency of feeding. In general the small oligotrichs (such as the entodiniomorph species) appear to predominate in the rumen of cattle and sheep fed on grain- or molasses-based diets (Schwartz \& Gilchrist, 1975; D. Ffoulkes and R. A. Leng, unpublished results) whereas large populations of holotrichs such as Isotricha and Dasytricha spp. tend to predominate in the rumen of animals fed on fresh grass or other diets of relatively high soluble-sugar content. For instance, the large protozoa occur in large numbers in the rumen of cattle grazing green temperate pasture (Clarke, 1965) or fed on sugar-cane-based diets (Valdez et al. 1977).

The holotrich protozoa have a slow turnover rate in the rumen of animals fed on sugar-cane-based diets (Leng et al. 1981) and are apparently retained for long periods in the rumen. The smaller Entodinium spp. of protozoa appear to have a relatively higher turnover rate (D. Ffoulkes and R. A. Leng, unpublished results). However, both groups of protozoa turnover at a slower rate than the liquid pool in the rumen (Leng et al. 1981, 1984; Leng, $1982 b$; D. Ffoulkes and R. A. Leng, unpublished results).

Understanding the role of protozoa has become important because of the effect that a large biomass of protozoa in the rumen may have on the efficiency of utilization of feed by ruminants, in particular through their engulfment of bacteria. Knowledge of the dynamics of the holotrich protozoa is essential for understanding the likely role of these protozoa in rumen fermentative digestion.

In the present study we estimated the pool sizes and turnover rates of the large holotrich protozoa in the rumen of cattle fed on freshly harvested green grass. The results are discussed in relation to previous findings on the dynamics of holotrich protozoa in the rumen of cattle given sugar-cane-based diets (Leng et al. 1981). 


\section{MATERIALS AND METHODS}

\section{Experimental animals}

Mature crossbred cows (five Friesian $\times$ Jersey, one Ayrshire) weighing 450 (SE 68) kg live weight and with permanent rumen cannulas were fed ad lib. on freshly harvested ryegrass (Grasslands Moatu Lolium multiflorium Lam) twice daily at 08.00 hours and 14.00 hours. The grass was in a leafy growth stage. The animals consumed about $4.5 \mathrm{~kg}$ dry matter (DM) in the morning and $2.2 \mathrm{~kg} \mathrm{DM}$ in the evening, giving a total intake of $6.7 \mathrm{~kg} \mathrm{DM}$ or $50 \mathrm{~kg}$ wet pasture daily. Drinking water was available at all times.

The cows were held on a sawdust resting pad at night and moved into an animal house during the day.

\section{Experimental procedures}

Measurement of dynamics of protozoa. On the day of administration of labelled protozoa, the cattle were held in individual pens in an animal house. At $1-2 \mathrm{~h}$ after feeding at 08.00 hours, rumen samples were obtained from each cow for preparation of ${ }^{14} \mathrm{C}$-labelled protozoa. Immediately before the injection of labelled protozoa at about 13.00 hours, CrEDTA was injected intraruminally to enable estimates to be made of liquid volume and rate of outflow from the rumen. Samples of rumen fluid were taken at regular intervals for enumeration of protozoa (Warner, 1962). Samples of rumen fluid were taken hourly over the 1st day for the estimation of chromium. Commencing on the day after injection of the labelled protozoa, samples of rumen fluid were taken from the animals each day for $5 \mathrm{~d}$ between 09.00 and 11.00 hours for the estimation of the specific radioactivity (SR) of protozoa. Samples of rumen gas were also taken for determination of methane SR at 10.00 and 18.00 hours for $5 \mathrm{~d}$ following injection of labelled protozoa.

Preparation of ${ }^{14} \mathrm{C}$-labelled protozoa and injection procedures. Rumen fluid $(400 \mathrm{ml})$ was obtained from each cow by gentle suction through a plastic tube attached to a gauze-covered, perforated stainless-steel probe situated some $400 \mathrm{~mm}$ into the dorsal part of the rumen. The fluid was immediately placed in a separatory funnel, previously warmed to $39^{\circ}$, and allowed to stand in an incubator at $39^{\circ}$. Large protozoa collected in the lower parts of the funnel and, after about $3 \mathrm{~min}, 200 \mathrm{ml}$ of the protozoa-enriched rumen fluid was run into a $250 \mathrm{ml}$ conical flask containing $2 \mathrm{mg} 250 \mu \mathrm{Ci}\left[\mathrm{Me}-{ }^{14} \mathrm{C}\right.$ ]choline (Amersham International plc, Amersham, Bucks) in $10 \mathrm{ml}$ isotonic saline ( 9 g sodium chloride/ 1$)$. The flask was then incubated in a water bath for $2 \mathrm{~h}$ at $39^{\circ}$ and shaken eighty times $/ \mathrm{min}$. The flask was also shaken by hand at about 5 -min intervals to prevent the protozoa collecting on the bottom of the flask. After incubation, the flask contents were centrifuged in $50 \mathrm{ml}$ tubes at $500 \mathrm{~g}$ for $1 \mathrm{~min}$ and the supernatant discarded. The residue was resuspended in rumen fluid collected a few minutes previously from the cow from which the protozoa were originally taken. A small amount of this suspension was taken for assay of radioactivity in the protozoa and the rest was injected into the rumen of the cow from which the original sample had been obtained.

Isolation of protozoa for assay of radioactivity. Samples $(2 \times 10 \mathrm{ml})$ were taken at the end of the incubation period from the labelled protozoa preparation whilst shaking them vigorously to ensure the protozoa were representatively sampled. These samples were placed in centrifuge tubes and the protozoa washed and isolated as indicated for other samples, except that following centrifugation, particular care was taken not to remove any of the protozoal pellet. The pellet was finally washed into a $50 \mathrm{ml}$ volumetric flask and made up to volume with isotonic saline. Four representative subsamples $(0.5 \mathrm{ml})$ were then placed in a vial with $10 \mathrm{ml}$ scintillation fluid and the radioactivity determined.

$S R$ of protozoa in rumen fluid samples. Two samples of rumen fluid $(50 \mathrm{ml})$ were taken within $5 \mathrm{~min}$ of each other from the rumen directly into a plastic syringe and transferred 
to $50 \mathrm{ml}$ separatory funnels, previously warmed to $39^{\circ}$, and held in an incubator at $39^{\circ}$ These were left for $3 \mathrm{~min}$ to allow the large protozoa to settle. Then $20 \mathrm{ml}$ of the rumen fluid (which was enriched with large protozoa) were run into a centrifuge tube. This was centrifuged at $500 \mathrm{~g}$ for $1 \mathrm{~min}$ and the supernatant quickly poured off. The pellet was mixed with formal saline and the centrifugation repeated. Following the removal of the supernatant fluid a considerable proportion of the upper layers of plant material and small protozoa could be removed by judicious washing of the pellet, before resuspension of the remaining protozoa in isotonic saline and centrifuging. The protozoa were then washed in this way twice with isotonic saline. Following the final wash, the protozoa were resuspended in $2 \mathrm{ml}$ isotonic saline and, whilst agitating the suspension on a vortex mixer to ensure the protozoa were evenly distributed throughout the suspension, $0.5 \mathrm{ml}$ was pipetted into a scintillation vial, $0.5 \mathrm{ml}$ water and $10 \mathrm{ml}$ of scintillating mixture were added to enable assay of radioactivity (see Leng, $1982 b$ ) and $0.5 \mathrm{ml}$ was placed into a Kjeldahl flask for estimation of total nitrogen. Following acid digestion (for $2 \mathrm{~h}$ at $350^{\circ}$ ), ammonia was estimated by an autoanalyser method based on the reaction of alkaline phenol and hypochlorite to give indophenol (Clare \& Stevenson, 1964). The results from the two rumen samples taken serially were averaged.

Samples of the smaller entodiniomorph protozoa were also isolated from rumen fluid by the method of Leng (1982b).

Methane production rate in the rumen was measured using methods described by Leng $\left(1982 b\right.$ ). Commencing at about 09.00 hours, ${ }^{14} \mathrm{CH}_{4}$ (Amersham International plc) was infused $(1 \cdot 0 \mu \mathrm{Ci}, 0.1 \mathrm{mg} / \mathrm{ml}, 2 \mathrm{ml} / \mathrm{min})$ through a metal tube into the dorsal sac of the rumen for $14 \mathrm{~h}$. Samples $(10 \mathrm{ml})$ were collected from the rumen gas space at hourly intervals between 3 and $14 \mathrm{~h}$ after infusion. Smaller samples $(2 \mathrm{ml})$ were also collected every $15 \mathrm{~min}$ over the same period. These latter samples were bulked for each hour before analysis. The SR of methane was determined as described by Leng $(1982 b)$.

\section{Chemical analysis}

Total $\mathrm{N}$ in feed was determined by the Kjeldahl method, DM by heating at $70^{\circ}$ in a forced-draught oven for $16 \mathrm{~h}$ and ash by combustion of the dried sample at $500^{\circ}$ for $8 \mathrm{~h}$. Lipid content of the cut pasture material was determined by the method of Folch et al. (1957). Acid-detergent fibre (ADF), neutral-detergent fibre (NDF) and lignin were measured according to the methods of Goering \& Van Soest (1975). Energy content was estimated using an adiabatic bomb calorimeter (Gallenkamp).

Water-soluble sugar, starch and pectin were estimated according to the methods of Bailey (1958) and Blaumenkrantz \& Asboe-Hansen (1973), and $\mathrm{Cr}$ in rumen fluid was estimated using an atomic absorption spectrometer with a nitrous oxide-acetylene flame.

\section{Calculations}

Rumen volume and liquid flow rate from the rumen were determined from the decline in the concentration of $\mathrm{Cr}$ in rumen fluid over $24 \mathrm{~h}$ following the injection of CrEDTA according to the method of Downes \& McDonald (1964).

The pool size and apparent production rate of protozoa were calculated assuming a single pool of protozoa in steady-state existed in the rumen as described by Leng $(1982 b)$. The estimate of protozoal lysis was made by the procedure described and discussed by Leng $(1982 b)$. 
Table 1. Rumen fluid volumes determined by dilution of CrEDTA and mean protozoal numbers in the rumen of cattle fed on ryegrass (Lolium multifiorium Lam)-based diets

(The measurements were made on $1 \mathrm{~d}$ at the end of the study. The protozoal numbers are expressed as means and ranges in samples taken at 30 -min intervals from before feeding in the morning to before feeding in the evening)

\begin{tabular}{|c|c|c|c|c|c|c|c|c|c|}
\hline \multirow{3}{*}{$\begin{array}{c}\text { Cow } \\
\text { no. }\end{array}$} & \multirow{2}{*}{\multicolumn{2}{|c|}{$\begin{array}{l}\text { Pasture dry } \\
\text { matter intake } \\
(\mathrm{kg} / \mathrm{d})\end{array}$}} & \multirow{3}{*}{$\begin{array}{l}\text { Rumen } \\
\text { volume } \\
\text { (1) }\end{array}$} & \multirow{3}{*}{$\begin{array}{l}\text { Rumen } \\
\text { fluid } \\
\text { half-life } \\
\text { (min) }\end{array}$} & \multirow{3}{*}{$\begin{array}{l}\text { Rumen } \\
\text { fluid } \\
\text { outflow } \\
\text { rate } \\
\text { (l/d) }\end{array}$} & \multicolumn{4}{|c|}{$\begin{array}{l}\text { Protozoal numbers in } \\
\text { rumen fluid }\left(\times 10^{-4} / \mathrm{ml}\right)^{\dagger}\end{array}$} \\
\hline & & & & & & \multicolumn{2}{|c|}{ Large protozoa } & \multicolumn{2}{|c|}{ Small protozoa } \\
\hline & Mean* & SE & & & & Mean & Range & Mean & Range \\
\hline 1 & $6 \cdot 5$ & 0.56 & 41 & 399 & 102 & $3 \cdot 7$ & $4 \cdot 9-2 \cdot 0$ & $4 \cdot 7$ & $8 \cdot 1-3 \cdot 3$ \\
\hline 2 & $7 \cdot 6$ & 0.56 & 47 & 394 & 177 & $5 \cdot 0$ & $8 \cdot 1-2 \cdot 7$ & $0 \cdot 9$ & $1.9-0.4$ \\
\hline 3 & $6 \cdot 2$ & 0.50 & 41 & 443 & 92 & $4 \cdot 1$ & $7 \cdot 5-2 \cdot 3$ & $1 \cdot 0$ & $1 \cdot 3-0.9$ \\
\hline 4 & $7 \cdot 5$ & 0.45 & 51 & 370 & 139 & 4.9 & $8 \cdot 9-2 \cdot 6$ & $2 \cdot 8$ & $5 \cdot 2-1 \cdot 1$ \\
\hline 5 & $5 \cdot 4$ & 0.55 & 33 & 320 & 103 & $5 \cdot 7$ & $10 \cdot 1-3 \cdot 2$ & $2 \cdot 0$ & $2 \cdot 4-1 \cdot 5$ \\
\hline 6 & $6 \cdot 6$ & 0.56 & 48 & 313 & 154 & $5 \cdot 4$ & $11 \cdot 6-1 \cdot 3$ & $3 \cdot 5$ & $4 \cdot 1-0 \cdot 6$ \\
\hline
\end{tabular}

* Mean measured over the $7 \mathrm{~d}$ experimental period.

$\uparrow$ Mean and range of fourteen samples taken from 07.00 to 14.00 hours. The large protozoa were about equal numbers of Isotricha and Dasytricha spp. The small protozoa were about $90 \%$ Entodinium spp.

Table 2. Dynamics of large ciliate protozoa in the rumen of cattle fed on ryegrass (Lolium multiflorium Lam)-based diets as estimated using ${ }^{14} \mathrm{C}$-labelled protozoa

\begin{tabular}{ccccc}
\hline Cow & $\begin{array}{c}\text { Pool } \\
\text { size } \\
\text { no. }\end{array}$ & $\begin{array}{c}\text { Half-life } \\
\text { (min) }\end{array}$ & $\begin{array}{c}\text { Protozoa apparent } \\
\text { production } \\
\text { rate } \\
(\mathrm{g} \mathrm{N} / \mathrm{d})\end{array}$ & $\begin{array}{c}\text { Apparent } \\
\text { lysis } \\
\text { rate } \\
(\%)\end{array}$ \\
\hline 1 & $19 \cdot 6$ & 2246 & 8.7 & 69 \\
2 & 11.5 & 2075 & 5.5 & 45 \\
3 & 10.5 & 2166 & 4.9 & 100 \\
4 & $25 \cdot 6$ & 2213 & 11.6 & 67 \\
5 & $9 \cdot 5$ & 1627 & 5.8 & 104 \\
6 & $13 \cdot 7$ & 1568 & 8.7 & 110 \\
\hline
\end{tabular}

\section{RESULTS}

The chemical composition ( $\mathrm{g} / \mathrm{kg} \mathrm{DM}$ ) of the pasture material given to the animals was as follows: crude protein 220 , water-soluble sugars 10 , starch 50 , pectin 14 , lipid 55, NDF 530 , ADF 390, lignin 40, ash 110 . The feed had a gross energy of $18.8 \mathrm{~kJ} / \mathrm{g} \mathrm{DM}$.

The relation of $\log$ CrEDTA concentration $v$. time was linear in all animals, and the mean volumes and rates of outflow of fluid, estimated by CrEDTA dilution, are shown in Table 1.

The number of protozoa in the rumen fluid samples varied with time after feeding. For up to $4 \mathrm{~h}$ after feeding the large ciliates predominated. The mean and range of protozoal numbers over the period $09.00-14.00$ hours in rumen fluid are given in Table 1 .

The procedure used to prepare labelled protozoa for injection into the rumen increased the numbers of large ciliates in the sample so that there was a value of $6: 1$ for large ciliates relative to other protozoa. The procedures used to isolate protozoa for assay of $\mathrm{N}$ and radioactivity from samples of rumen fluid also resulted in a similar concentration of large 


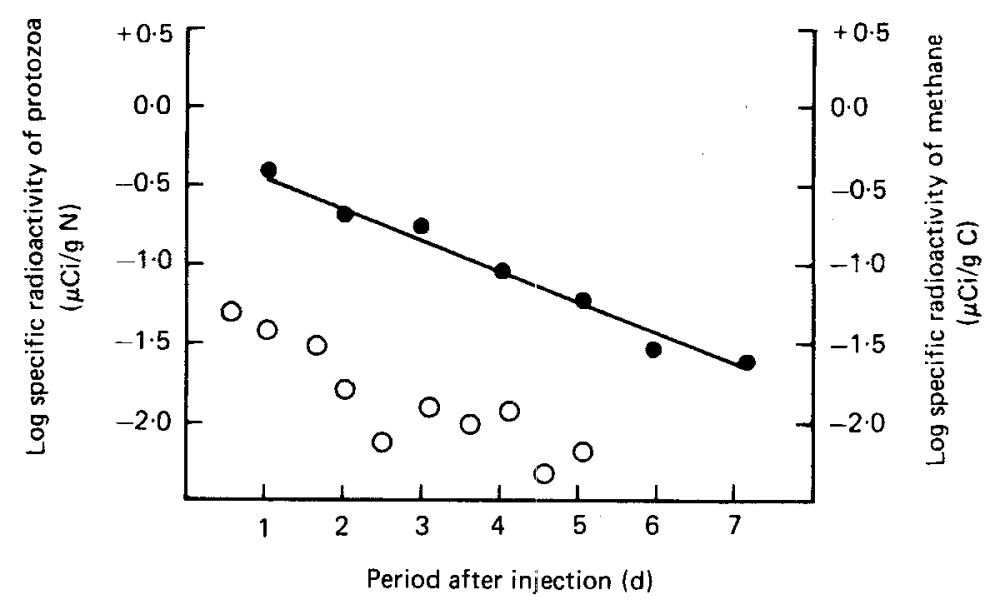

Fig. 1. Specific radioactivity $(\mu \mathrm{Ci} / \mathrm{g}$ nitrogen) of protozoa isolated from the rumen following injection of ${ }^{14} \mathrm{C}$-labelled protozoa. Specific radioactivity of methane is also shown. Specific radioactivities of protozoa $(O)$ and methane $(\mathrm{O})$.

protozoa. The 'contamination' of the large ciliates with smaller protozoa was therefore always small. Isolation of the smaller protozoa showed that their contribution to mass was less than $0.5 \%$ and their radioactivity was less than $1 \%$ of that in injected dose. The smaller protozoa contained virtually no radioactivity $24 \mathrm{~h}$ after the injection of labelled protozoa.

The $\log$ SR of the isolated large protozoa for seven estimates of SR taken over $7 \mathrm{~d}$ declined linearly with time (see Fig. 1). The correlation coefficient $\left(R^{2}\right)$ for these relations in the six cows was between 0.94 and 0.97 . The pool size, half-life and apparent production rate of these large protozoa are given in Table 2.

The SR of methane was variable during the infusion of ${ }^{14} \mathrm{CH}_{4}$ even over the period when plateau SR should have been reached. The methane production rate was calculated from the mean SR over the period from 3 to $14 \mathrm{~h}$ after an infusion. Methane production rate in the six animals varied from 80 to $106 \mathrm{mg} \mathrm{C} / \mathrm{min}$ with a mean of $95 \mathrm{mg} \mathrm{C} / \mathrm{min}$.

The SR of methane over the $5 \mathrm{~d}$ following injection of ${ }^{14} \mathrm{C}$-labelled protozoa into the rumen is given in Fig. 1. The SR was too low after day 5 to be satisfactorily estimated and no further samples were taken. The area under the curve for SR of methane $v$. time, to time infinity, multiplied by the mean production rate of methane gave an estimate of the amount of radioactivity lost via the methane pool and thus the rate of lysis of protozoa in the rumen (Table 2).

\section{DISCUSSION}

Preliminary studies confirmed that between 1 and $4 \mathrm{~h}$ after feeding in the morning, the large ciliates of the species Isotricha and Dasytricha were numerically predominant. They are considerably larger than the entodinia (the other protozoa species present in significant numbers in the rumen) and they accounted for most of the protozoal biomass in the fluid phase. As the present study was primarily concerned with the dynamics of the larger protozoa, the samples of rumen fluid for preparation of the labelled protozoa were taken approximately $1 \mathrm{~h}$ after feeding. Also the samples of rumen fluid were taken at this time each day for isolation and assay of the SR of large ciliate protozoa.

To ensure that the kinetics of the holotrich protozoa were correctly assessed it was 
necessary to obtain, as far as possible, 'uncontaminated' holotrich protozoa from the rumen for initial labelling and also for estimation of their specific radioactivity following introduction of the labelled protozoa into the rumen. Errors associated with cannibalism between protozoan species with resultant transfer of label were also minimized by ensuring that the holotrichs were isolated free of other species which may become labelled.

The protozoal samples isolated for determination of SR contained all the species of protozoa present in the rumen; some $14-20 \%$ of the protozoa were the small ciliates (i.e. about $20 \mu \mathrm{m}$ in diameter) but they probably represented less than $2 \%$ of the total biomass isolated (see Clarke et al. 1982). These small protozoa contained no detectable radioactivity after $24 \mathrm{~h}$. Thus this contamination probably had no measurable effect on the estimates of $\mathrm{SR}$ of the large protozoa, and it was assumed that all the $\mathrm{N}$ and radioactivity in the sample were from the large protozoa.

As with cattle fed on sugar cane (see Valdez et al. 1977), the numbers of large protozoa in samples taken from the rumen fluid with a probe inserted into the dorsal sac of the rumen follow a characteristic pattern after feeding (Clarke, 1965). Numbers in the fluid are high for some time after feeding, falling to low levels before the next feeding period, indicating that these protozoa sequester somewhere in the rumen. Sequestration appears to allow protozoa to be retained in the rumen (see Weller \& Pilgrim, 1974). Sequestered holotrichs occupy specific sites on feed particles in the rumen (see Bauchop, 1980) but appear to release themselves from these sites when the animal consumes food, presumably in response to soluble components entering the rumen fluid (see Murphy et al. 1985).

Superficially, it might appear that sequestration of protozoa after feeding could compromise the assumption of a steady-state in the protozoal pool that is needed for the tracer analysis used in the present study. In fact the opposite is true. Sequestration of protozoa and their subsequent appearance in the sampled rumen fluid after each feeding would facilitate the mixing of labelled protozoa throughout the sequestered and non-sequestered components of the total protozoal pool. Thus holotrich protozoa are at times free in the fluid phase, from which they are easily sampled, or occupy some niche which is not easily sampled. The sequestered pool appears to contain virtually all the holotrichs just before feeding in once-a-day fed animals. On the other hand, the liquid pool contains all the holotrichs for 3-4 h following feeding (Clarke, 1965; Valdez et al. 1977; Murphy et al. 1985). The protozoa in the two niches may be regarded as separate entities which freely mix when protozoa release from their sequestered sites. Murphy et al. (1985) showed that placing food directly into the rumen on two occasions per day caused protozoa to appear in high numbers (threefold the prefeeding numbers) immediately following each addition.

Since the exchange of protozoa between the two pools is rapid, relative to the turnover of the total holotrich population, the two entities may be regarded as a single pool and the SR-time relation as a single exponential function (Shipley \& Clark, 1972). The injected dose divided by the SR at the time of injection (determined by extrapolation) is therefore a good estimate of the combined size of the individual entities and therefore the total biomass of holotrich protozoa in the rumen. The slow turnover (see later) of the labelled protozoa is itself indicative of a low rate of growth of protozoa in the rumen and a slow rate of loss, either by lysis or by passage into the omasum with digesta. The pool size must therefore remain fairly static and the average rate of outflow from the pool can be satisfactorily estimated by taking samples only once each day, at the same time, as was done in the present experiment.

The SR $v$. time curve for the large holotrich protozoa over $7 \mathrm{~d}$ was well described by a single exponential function (Fig. 1) indicating that, despite the relatively short-term changes over $1 \mathrm{~d}$ in the proportions of protozoal biomass in the fluid and sequestered phases, protozoal growth and removal obeyed first-order kinetic processes. The results indicate that 
the mean turnover of the large ciliate protozoa in cows fed on freshly harvested ryegrass was $1 \cdot 5-2 \cdot 3 \mathrm{~d}$, i.e. three to five times longer than the turnover time of rumen fluid.

The turnover time of large ciliate protozoa was appreciably shorter than that of the same species of protozoa in the rumen of cattle fed on sugar-cane-based diets, i.e. between 8 and $21 \mathrm{~d}$ (Leng et al. 1981). In the latter study only three animals were examined. In those animals, following injection of ${ }^{14} \mathrm{C}$-labelled protozoa, two distinct rate-constants of labelled protozoa were apparent, one $0-5 \mathrm{~d}$ and another 5-13 d post-infusion. Only one component was apparent in the SR-time relation in the six cattle studied here. The mean turnover time for this protozoal pool was $2 \cdot 0 \mathrm{~d}$.

The earlier results, together with those now reported, suggest that the growth rates of protozoa may change with changing conditions in the rumen. The larger protozoal pool in the rumen of cattle fed on sugar-cane-based diets $(25-40 \mathrm{~g} \mathrm{~N})$, and the slower apparent growth rate, compared with the same species of protozoa in the rumen of cattle fed on a fresh ryegrass diet $(9 \cdot 5-23.6 \mathrm{~g} \mathrm{~N})$ (present study) suggest that the rate of protozoal growth at high population densities of protozoa may be limited by the availability of essential nutrients. If so, apparent production of protozoa in the rumen would be dependent on nutrient availability and not on the biomass present.

Protozoa in the rumen have been observed to disappear (die?) suddenly (Rowe, 1978), perhaps due to changes in $\mathrm{pH}$, osmolarity or even temperature (Coleman, 1985). In the present study a sudden death and loss of a proportion of the protozoal pool would have no affect on its SR. However, if the decreased population resulted in an increased growth rate of protozoa, this could explain the two-component relations previously reported (Leng et al. 1981). It is, however, apparent that growth and death rates plus loss to the lower tract are generally fairly constant and that catastrophic death rates are a sporadic and unusual happening.

Leng (1984) showed a marked difference in the turnover times of Entodinium and Polyplastron spp. in the rumen of sheep, and the relation between pool size and apparent production for the larger holotrich protozoa is significantly different from that for the smaller entodinia in the rumen of cattle (D. Ffoulkes and R. A. Leng, unpublished results), indicating different dynamics for the different protozoal species.

The turnover time of species of small protozoa, mainly entodinia, in the rumen of cattle has been shown previously to be similar to that of entodinia in the rumen of sheep, i.e. approximately $24 \mathrm{~h}$ (Leng, 1982 b; D. Ffoulkes and R. A. Leng, unpublished results) whereas in the present study the turnover of the holotrichs was a little under $48 \mathrm{~h}$.

The extent of lysis of the large ciliates in the rumen was estimated in the present study from the flow of ${ }^{14} \mathrm{C}$, released through the rumen methane pool (see Leng, 1982b). It has previously been shown that methane is the only route of loss of ${ }^{14} \mathrm{C}$, as bacteria do not incorporate $\left[{ }^{14} \mathrm{C}\right]$ choline and, because rumen bacteria rapidly degrade choline, they also apparently prevent measurable reincorporation by protozoa (Leng, 1982b).

Methane production rate, as measured by using ${ }^{14} \mathrm{CH}_{4}$, was variable and seemed to reflect expected changes in fermentation rates in the rumen associated with the twice daily feeding regimen. Methane-production-rate estimates in the present study ( $95 \mathrm{mg} \mathrm{C} / \mathrm{min})$ were close to those predicted from stoichiometric principles for these digestible organic matter intakes (see Leng, 1982a). Methane production rate, and the ${ }^{14} \mathrm{C}$ from labelled protozoa passing through the methane pool, are clearly only very crude estimates and are used here only to give a rough indication of the extent of lysis of protozoa in the rumen. On this basis, lysis appeared to account for a very high proportion of the protozoal turnover rate.

The net microbial yield in the rumen appears to be about $30 \mathrm{~g} \mathrm{~N} / \mathrm{kg}$ organic matter apparently digested in the rumen (Roy et al. 1977). The animals used in these studies were consuming, on average, $6.75 \mathrm{~kg} \mathrm{DM} / \mathrm{d}$, representing about $4.2 \mathrm{~kg}$ organic matter 
digested. If $70 \%$ of organic matter were fermented in the rumen the net protein synthesis in the rumen micro-organisms would be about $90 \mathrm{~g} \mathrm{~N} / \mathrm{d}$. This large population of large protozoa only synthesized $7-8 \mathrm{~g} \mathrm{~N} / \mathrm{d}$ or about $9 \%$ of the possible microbial protein yield.

The low growth rate of protozoa and their possibly high requirements for energy/unit mass for maintenance, and the possibility of significant engulfment of bacteria by protozoa all suggest that a major effect of protozoa is to lower the availability of microbial protein in ruminants fed on diets high in readily fermentable carbohydrate. Thus amino acid$\mathrm{N}$ : energy value in the products of fermentative digestion of grazing ruminants is likely to be lower where protozoal populations in the rumen are high.

The results indicate that the large ciliate protozoa are extensively retained in the rumen and have a long life. Thus, most protozoa do not leave the rumen in digesta and therefore eventually die, and are degraded, in the rumen.

The authors would like to thank the Australian Meat Research Committee for financial support for this project. The following gave valuable technical assistance: V. Scollen, R. Wicks, S. Stachiw and F. Ball. Other technical assistance by J. Kook, A. Alan, C. Gurnsey and G. Filbey is gratefully acknowledged.

\section{REFERENCES}

Bailey, R. W. (1958). Biochemistry Journal 68, 669-672.

Bauchop, T. (1980). In Contemporary Microbial Ecology, pp. 305-326 [D. C. Ellwood, J. N. Hedgerz, M. J. Latham, J. M. Lynch and J. H. Slater, editors]. Academic Press: London.

Blaumenkrantz, N. \& Asboe-Hansen, G. (1973). Analytical Biochemistry 54, 484489.

Clare, N. T. \& Stevenson, A. E. (1964). New Zealand Journal of Agricultural Research 7, $198-204$.

Clarke, R. T. J. (1965). New Zealand Journal of Agricultural Research 8, 1-6.

Clarke, R. T. J., Ulyatt, M. J. \& Andrew, J. (1982). Applied and Environmental Microbiology 43, 1201-1204.

Coleman, G. S. (1985). Journal of Agricultural Science, Cambridge 105, 3943.

Downes, A. M. \& McDonald, I. W. (1964). British Journal of Nutrition 18, 153-162.

Folch, J., Lees, M. \& Sloane-Stanley, G. H. (1957). Journal of Biological Chemistry 226, 479-509.

Goering, H. K. \& Van Soest, P. J. (1975). Forage Fibre Analyses, Agriculture Handbook, United States Department of Agriculture, p. 379. Washington, DC: United States Department of Agriculture.

Leng, R. A. (1982a). In Nutritional Limits to Animal Production from Pastures - an International Symposium, pp. 427-453 [J. B. Hacker, editor]. Farnham Royal: Commonwealth Agricultural Bureaux.

Leng, R. A. (1982 b). British Journal of Nutrition 48, 399-415.

Leng, R. A. (1984). Proceedings of the Australian Society of Animal Production 15, 428-430.

Leng, R. A., Gill, M., Kempton, T. J., Rowe, J. B., Nolan, J. V., Stachiw, S. J. \& Preston, T. R. (1981). British Journal of Nutrition 46, 371-384.

Leng, R. A., Nolan, J. V., Cumming, R., Edwards, S. R. \& Graham, C. A. (1984). Journal of Agricultural Science, Cambridge 102, 609-613.

Murphy, M. R., Drone, P. E. and Woodford, S. T. (1985). Applied and Environmental Microbiology 49, 1329-1331.

Rowe, J. B. (1978). Studies on the interrelationship between fermentation, digestion and metabolism in sheep. $\mathrm{PhD}$ Thesis, University of New England, Armidale, Australia.

Roy, J. H. B., Balch, C. C., Miler, E. L., Ørskov, E. R. \& Smith, R. H. (1977). In Proceedings of the 2nd International Symposium on Protein Metabolism and Nutrition, pp. 126-129. EAAP Publication no. 22. Wageningen: Pudoc.

Schwartz, H. M. \& Gilchrist, F. M. C. (1975). In Digestion and Metabolism in the Ruminant, pp. 165-179 [I. W. McDonald and A. C. I. Warner, editors]. Armidale, Australia: University of New England Publishing Unit.

Shipley, R. A. and Clark, R. E. (1972). Tracer Methods for in Vivo Kinetics. New York: Academic Press.

Valdez, R. E., Alvares, F. J., Ferreiro, H. M., Guerra, F., Lopez, J., Priego, A., Blackburn, T. H., Leng, R. A. \& Preston, T. R. (1977). Tropical Animal Production 2, 260-270.

Warner, A. C. I. (1962). Journal of General Microbiology 28, 119-128.

Weller, R. A. \& Pilgrim, A. F. (1974). British Journal of Nutrition 32, 341-351. 